\title{
Evaluation of Public Spokespersons
}

\author{
Flemming Hansen \& Christian Kock
}

\begin{abstract}
...but when I was speaking in America, they told me that there were 105 million TV sets in America ... It is a strange feeling to speak to millions of people. I think one feels it. There is something strange about television, very odd, also in another way. They told me over there that television is dangerous, it gives you away, you can't hide your true nature, appearing on television. They said that McCarthy, then a very popular person, was ruined in one or two days, after appearing on television. People did not believe him, or they did not trust him any more.... In general, people who appeared on television over there were kind of "waterproof". (Quotation from radio interview with Karen Blixen, 1955)
\end{abstract}

In our generation, audio-visual media have become a dominant force in the public arena, for political debate, transmission of news, business, and for many other purposes. In this context, the credibility of public persons has become an important item in the public sphere. For example, in Denmark the current Prime Minister, Mr Poul Nyrup Rasmussen, is said by many commentators to have a severe "credibility problem". This liability is said to have brought him defeat in the referendum he had called on the common European currency in September, 2000 , which was won by the anti-Euro coalition, and it is also cited as grounds for his likely upset in the upcoming general election. Such claims are current in spite of the fact that Mr. Nyrup Rasmussen's administration is admitted to have performed well

Department of Marketing, Copenhagen Business School, Solbjerg Plads 3, DK-2000 Frederiksberg, fh.marktg@cbs.dk

Department of Education, Philosophy and Rhetoric, Copenhagen University, Njalsgade 80, DK-2300 CopenhagenS, kock@hum.ku.dk by objective standards, at least as far as the economy is concerned.

It is not a new fact that credibility is considered important. For the last 50 years or so, communication scholars have studied it intensively. Hovland et al. (1953) initiated this effort, Andersen \& Clevenger (1963) summarized work so far, followed by, among many others, J. McCroskey, (e.g., McCroskey 1966; Whitehead 1968; Tuppen 1974).

After the heyday of empirical credibility studies, a new facet to the issue came into focus as television became the main source of political and other public communication. The ability to communicate well on TV was highlighted in the 1980 'es in press commentaries as well as scholarly studies centering on President Ronald Reagan as a "master communicator". Reagan's masterful handling of the specific demands of this all-important medium were scrutinized. Since then, it has been a standard assumption that the ability to perform well on TV and in other mass-mediated contexts is crucial to success in politics as well as in business and public opinion generally, and there is a strong tendency to equate the notion of a source's credibility with that source's ability to handle TV and other media well and to "come across" in a way that will ingratiate viewers.

That raises the question as to what connection there might be between these two constructs: 1) credibility, as analyzed in the many empirical studies since the 50'es, and 2) the status as mass-mediated "master communicator," as instantiated by Ronald Reagan, or in later decades, Bill Clinton or British PM Tony Blair. Are these two constructs basically the same? Or are they different but correlated? Or are they perhaps clearly separate?

To return to the case of Prime Minister Nyrup Rasmussen, it is generally said not only that his credibility is low, but also that his performance on $\mathrm{TV}$ is often toe-cringing. One way to see such a case is to conclude that credibility and the qualities that 
make a master communicator are closely connected, and that this is why a public figure would rank low in both respects.

On the other hand, there are observations that might suggest a different hypothesis. A point of departure for this study has been the regular appearance of credibility ratings for public persons, media, and organizations. On source of such ratings in Denmark has been the business weekly B $\phi$ rsens Nyhedsmagasin, which publishes an annual "credibility barometer". More than once, we have been struck by the fact that the people and organizations usually considered "master communicators" - for example those politicians most praised by the media and by communication experts as being "telegenic", capable of "coming across" on TV, of communicating in "headlines", etc. - are often quite low on the list. Conversely, figures or organizations at the top of the list are generally such as usually such as appear to lack or to shun these qualities; more typically, they appear thoughtful, balanced, measured, and even reticent in their media appearances.

From these observations we have built the hypothesis that in this age of mass-mediated communication there might well be more than one dimension on which the public communication of, e.g., politicians and organizations is evaluated by the general public. Further, we hypothesize that these dimensions may well be separate and perhaps even negatively correlated. Specifically, we hypothesize that the "master communicator" dimension might be separate from the "credibility" construct.

In studies done over the last decades, scholars have tended to find that credibility has as one of its dimensions a factor revolving around "dynamism" or "charisma". The work of Berlo \& al. (1969) has been influential in this respect.

At the same time, however, one of the originators, and perhaps the key figure, of this whole line of research, J.C. McCroskey, was beginning to doubt its soundness of the direction it was taking (McCroskey \& Young 1981). He felt that credibility scholars, including himself, had distorted the credibility construct by including an ever wider battery of descriptors, while still assuming that they were dealing with the same concept: credibility (or as McCroskey preferred to call it: ethos). By doing this they confounded credibility with other source characteristics unrelated to it. Source credibility, McCroskey now found, was merely a subset of a much larger construct of "person perception," and scholars would have done well to limit their factor analysis of it to the original Aristotelian ethos construct, with its main factors of competence (phronesis), moral character (arete), and good will towards the audience (eunoia) - a formula which had proved its robustness in one empirical study after the other, including McCroskey's own.

The present study is based on a hypothesis that heeds McCroskey's warning: credibility, we hypothesize, is a quite narrow concept that is separate from other important and desirable source characteristics. Among these other desirable characteristics are, for example, "telegenic" qualities enabling a person to come across well on TV, as well as such personable qualities which might easily allow audiences to relate to and identify with that person.

In order to test this hypothesis, we have assembled a set of scales that might be involved in creating either of the overall impressions of a source that we wish to analyze.

Just as we believe that there is a tendency to confound unrelated aspects of source evaluation under the term "credibility," we also hypothesize that differentiation is called for in another respect: credibility, for different categories of public persons, may depend on different characteristics. This should really be a rather obvious point, yet is one that was not explicitly made in credibility research until Cronkhite and Liska (1976).

\section{Hypotheses}

To sum up: In the present study, we want to test the following hypotheses.

H1. Evaluation of public persons is made along several dimensions, among which credibility is one and just one.

$\mathrm{H} 2$. The dimension of credibility is separate from the dimension that might characterise telegenic "master communicators".

H3. Different public persons are evaluated differently, along several evaluative dimensions.

In testing these hypotheses, ideally, a large number of different public persons should be evaluated along a large number of scales. To do so, would result in a questionnaire so extensive that it was feared that it would influence the response-rate and the quality of the responses.

For this reason, it was chosen to limit the study to five different public persons, with expectedly very different profiles. 


\section{Method}

For the study, a battery of statements were developed, covering items that might be used meaningfully in describing public spokespersons.

After some sorting and testing, a battery of 45 items was decided upon. The battery includes statements of the type: "is informative", "is eloquent," etc.

In the study, five high-profile public figures were included. These were two well-known political leaders with very different political orientation: $\mathrm{Mr}$. Svend Auken (57), a leading Social Democrat, currently Minister of the Environment, and Ms. Pia Kjærsgaard (53), leader of the right-wing, anti-immigration Danish People's Party; Denmark's most notable businessman, Mr. Maersk McKinney Møller (87), owner of the huge and successful A.P. Møller group; Ms. Bodil Nyboe Andersen (60), Governor of the National Bank; and a celebrated sports personality who has moved into politics: Mr. Ulrik Wilbek (42), former manager of the Danish ladies' handball team, which he led to a series of international triumphs in the 90'es. Each of these persons was rated on a five-point Likert scale for each of the 45 statements. Respondents were 78 students in a graduate class of Marketing and Communication.

\section{Data Analysis}

Self-rating of the respondents' awareness of the five spokespersons was also included in the questionnaire.

The sample is in no way representative for the total Danish population. Since the respondents were graduate students in business economics, we find it surprising that Mr. Møller and Ms. Nyboe Andersen were judged by several to be "not very well-known"

In the following analysis, respondents' ratings of persons they do not know, or do not know very well, are excluded. Awareness and average scores and the primitive, self-rated credibility for the five public figures are shown in table 1. It is obvious that considerable variation in the data exists. The two most credible figures, by far, are the non-political Governor of the National Bank and the leading business personality, but they are also the least known.

Factor analysis was conducted for each of the five persons. It appears that the solutions emerging here has significant similarity across individuals. This we take as an indication that the dimensions along which the different public persons are evaluated are similar, even though the precise evaluation of the persons may differ markedly. For this reason, we decided to define the dimensions based upon a combined analysis for all five public spokespersons. In this manner, the number of observations on which the analyses are based is increased from 78 to 391 . The stability of the solution thereby improves significantly.

With three factors, 47 percent of the total variance in the data is accounted for. The essence of this solution is shown in table 2 .

The first factor, accounting for more than half of the explained variance, centers on credibility or trustworthyness, which comes out with the highest loading on all statements. This lends support to the notion that "credibility" is indeed a separate factor, and that its name is an apt one. Moreover, the loadings of the other statements on this factor suggest some of the aspects that enter into the perception of credibility. On average for the five public figures, to be "irritating" (not surprisingly) detracts from credibility, whereas the perceptions that a person is intelligent, objective, and competent add to it.

The second separate dimension in the evaluation of the five persons can be labelled "charisma". Public spokespersons having this characteristics are extrovert, entertaining, telegenic, passionate, and able to explain things in a down-to-earth manner. Such

\section{Table 1. Awareness}

\begin{tabular}{lccccc} 
& $\begin{array}{c}\text { Svend } \\
\text { Auken }\end{array}$ & $\begin{array}{c}\text { Pia } \\
\text { Kjærsgaard }\end{array}$ & $\begin{array}{c}\text { Maersk McKinney } \\
\text { Møller }\end{array}$ & $\begin{array}{c}\text { Bodil Nyboe } \\
\text { Andersen }\end{array}$ & $\begin{array}{c}\text { Ulrik } \\
\text { Wilbek }\end{array}$ \\
\hline Others & 1 & 1 & 1 & 5 & 1 \\
1. Not known & & & 11 & 28 & 3 \\
2 & 4 & 1 & 10 & 19 & 9 \\
3 & 15 & 9 & 18 & 12 & 16 \\
4 & 20 & 23 & 17 & 9 & 15 \\
5 & 25 & 31 & 16 & 4 & 23 \\
6. Very well known & 13 & 13 & 5 & 1 & 11 \\
\hline
\end{tabular}

Note: 1-6 reflect degrees of awareness, 6 being the highest, and $1=$ do not know. 
Table 2. Three-dimensional Solution

\begin{tabular}{|c|c|c|c|}
\hline & Factor I & Factor II & Factor III \\
\hline Credible & .88 & & \\
\hline Irritating & -.85 & & \\
\hline Objective & .80 & & \\
\hline Intelligent & .79 & & \\
\hline Competent & .78 & & \\
\hline Unappealing & -.77 & & \\
\hline Person I often agree with & .76 & & \\
\hline Extrovert & & .68 & \\
\hline Entertaining & & .67 & \\
\hline Does not pull his/her punches & & .59 & \\
\hline Telegenic & & .58 & \\
\hline Passionate & & .55 & \\
\hline Brings matters down to earth & & .54 & \\
\hline Has charisma & & .51 & \\
\hline Sensitive & & & .62 \\
\hline Warm & & & .60 \\
\hline Folksy & & & .53 \\
\hline Capable of admitting mistakes & & & .49 \\
\hline Incapable of admitting mistakes & & & -.47 \\
\hline Doesn't respect other people's opinions & & & -.43 \\
\hline Plain & & & 0.36 \\
\hline
\end{tabular}

people are the darlings of talkshow hosts and debate moderators on TV because they come across so well on the screen.

It is no surprise that this is a dimension in source evaluation. The interesting thing is that this dimension is separate from credibility proper. This finding may explain the observation which originally instigated this study: that political and public figures high in telegenic qualities and the ability to "sell tickets" on the screen (to translate a favourite Danish term) often ranked low in credibility ratings, while precisely people like Ms. Nyboe Andersen high in expertise, independence, and balance, but soft-spoken and low in media magnetism - were invariably rated most credible.

The third dimension has a more emotional side to it. Important traits of persons scoring high on this factor are sensitive, warm, folksy, plain, and able to admit mistakes. The common denominator to these perceptions might be a homey, "one-of-us" quality.

\section{Three-dimensional Evaluation of Spokespersons}

Having determined three dimensions along which people evaluate public persons, we may try to profile the five public spokespersons individually on the three dimensions. This we could do by averag- ing that person's scores on the more important items belonging to each of the three factors. A more sensitive and elaborate procedure, however, is to compute factor scores for each respondent's evaluation of each public person on each of the three dimensions. The average factor score for each dimension then represents the degree to which each of the three public persons is associated with that dimension. These scores are shown in table 3:

It is evident that the way in which the five spokespersons are regarded very differently. Maersk McKinney Møller is most credible, but he scores less well on the other factors. Least credible is Pia Kjærsgaard. However, along with a sports celebrity such as Ulrik Wilbek, the right-wing party leader scores highest on charisma. This dimension, however, is one where the low-key National Bank Governor, Bodil Nyboe Andersen, scores high, but on the other hand, she is the only one to come anywhere near Møller on credibility. On the emotional "one-of-us" dimension, Auken and especially Wilbek stand out.

\section{Results}

The analysis suggests that our evaluation of public persons takes place along several separate dimensions. Here, it has been proposed to work with a 
Table 3. Average Factor Scores for Each Dimension on Each Person

\begin{tabular}{lccc} 
& Factor I & Factor II & Factor III \\
\hline Svend Auken & -.24 & -.24 & .29 \\
Pia Kjærsgaard & -.91 & .43 & -.51 \\
Maersk Mckinney Møller & .70 & -.19 & -.54 \\
Bodil Nyboe Andersen & .52 & .50 & .00 \\
Ulrik Wilbek & -.07 & .51 & .77 \\
\hline
\end{tabular}

three-dimensional analysis: credibility, charisma, and "one-of-us" emotional appeal. This analysis supports our hypotheses 1 and 2: credibility is just one factor in the evaluation of a public communicator; and more specifically, credibility is separate from other qualities that public communicators may also wish to possess, such as a) charisma and b) "one-of-us" emotional appeal. To be even more specific: the much vaunted charismatic, "master communicator" quality that politicians and other public figures are often said to need in order to "come across" on TV is not the same thing as credibility.

To say this is not tantamount to saying that charismatic "master communicators" do not exist, or that the quality they possess is not a valuable and important one. Such a claim would fly in the face of facts, e.g., the case of Ms. Kjærsgaard, who is undoubtedly, in some way, a master communicator with charismatic traits. Such a figure is clearly effective and persuasive in terms of building popular support. That raises the intriguing question of what the different kinds of persuasiveness or effectiveness are that we find in communicators who are

\section{References}

Andersen, K. \& T. Clevenger, Jr. (1963) “A Summary of Experimental Research in Ethos". Speech Monographs 30, 59-78.

Berlo, D.K., J.B. Lemert, \& R.J. Mertz (1969) "Dimensions of Evaluating the Acceptability of Message Sources". Public Opinion Quarterly 33, 563-76.

Cronkhite, G., \& J. Liska. (1976) "A Critique of Factor Analytic Approaches to the Study of Credibility". Communication Monographs 43, 91-107. strong on each of our three dimensions: credibility, charisma, and "one-of-us" appeal, respectively. We began with a reference to the case of Denmark's Prime Minister, Poul Nyrup Rasmussen. Looking back, we may now state that although in many people's estimate he has neither credibility nor charisma, this should not lead anyone to think that the two dimensions are the same. They are identifiable and separate dimensions in the evaluation of public communicators.

Based upon the present study, it would be possible to devise a meaningful instrument (of manageable size) for the profiling of spokespersons along the three dimensions suggested here. More specifically, to judge credibility, one would concentrate on those items in the analysis that contribute most to the explanation of the credibility of the spokespersons. With regard to the second and third dimension, it would be recommendable to work with at least three statements for each, providing a total battery of 16-20 statements, to be used for each person to be evaluated.

McCroskey, J. C. 1966. "Scales for the Measurement of Ethos". Speech Monographs 33, 65-72.

McCroskey, J.C., \& T.J. Young (1981) "Ethos and Credibility: The Construct and Its Measurement After Three Decades". The Central States Speech Journal 32, 24-34.

Tuppen, C.J.S. (1974) "Dimensions of Communicator Credibility: An Oblique Solution," Speech Monographs 41, 253-60.

Whitehead, J.L.Jr. (1968) "Factors of Source Credibility". Quarterly Journal of Speech 54, 59-63. 